Check for updates

Cite this: Chem. Sci., 2019, 10, 9091

๑ All publication charges for this article have been paid for by the Royal Society of Chemistry

Received 27th June 2019

Accepted 1st August 2019

DOI: $10.1039 / \mathrm{c} 9 \mathrm{sc03161h}$

rsc.li/chemical-science

\title{
Oxygen self-sufficient NIR-activatable liposomes for tumor hypoxia regulation and photodynamic therapy $\uparrow$
}

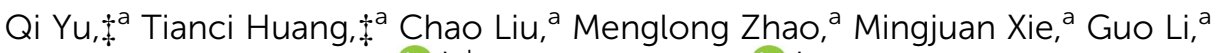 \\ Shujuan Liu, ${ }^{a}$ Wei Huang (D) *ab and Qiang Zhao (D) *a
}

\begin{abstract}
The inherent hypoxic environment in tumors severely resists the efficacy of photodynamic therapy. To address this problem, herein, the strategy of using oxygen self-sufficient liposomes (denoted as $\mathrm{CaO}_{2} /$ $\mathrm{B} 1 / \mathrm{NH}_{4} \mathrm{HCO}_{3}$ lipo), which contained aza-BODIPY dye (B1) and $\mathrm{CaO}_{2}$ nanoparticles in the hydrophobic layer and $\mathrm{NH}_{4} \mathrm{HCO}_{3}$ in the hydrophilic cavity, was presented to overcome hypoxia-associated photodynamic resistance. Under near-infrared (NIR) irradiation, NIR-absorbable B1 was activated to induce hyperthermia and further triggered the decomposition of $\mathrm{NH}_{4} \mathrm{HCO}_{3}$. Subsequently, with the aid of $\mathrm{NH}_{4} \mathrm{HCO}_{3}$ and $\mathrm{CaO}_{2}$ nanoparticles, oxygen was rapidly and self-sufficiently generated, during which clean by-products were produced. Furthermore, the increased amount of oxygen promoted the singlet oxygen production in the presence of B1, which served as a photosensitizer because of the heavy atom effect. The oxygen self-sufficient system improved the anticancer efficiency and alleviated the hypoxic environment in vivo, which demonstrated a valuable attempt to regulate intratumoral hypoxia and overcome the limitation of current photodynamic therapy systems. To our knowledge, this highlights the first example of using NIR light to activate $\mathrm{CaO}_{2}$ nanoparticle-containing liposomes for the modulation of the hypoxic environment in tumors.
\end{abstract}

\section{Introduction}

Hypoxia, one of the most remarkable features in tumorous microenvironments, has been demonstrated to be associated with many aspects of the activities of tumors, such as altered metabolism, unstabilized genome and metastasis. ${ }^{1-7}$ Moreover, it results in the limited response and resistance of treatments using antitumor drugs and radioactive reagents. ${ }^{8-11}$ Especially, the absence of adequate oxygen in tumors has been proved to largely influence the existing photodynamic therapy (PDT) systems, which mainly rely on a photosensitizing reagent to undergo the type II pathway to produce cytotoxic singlet oxygen $\left({ }^{1} \mathrm{O}_{2}\right)$ under photoexcitation. ${ }^{12-20}$ Moreover, the hypoxic environment can be further aggravated because of oxygen consumption during the PDT process. ${ }^{21,22}$ To overcome the intratumoral hypoxia, many oxygen-generating materials have been developed to supply oxygen, such as oxygen loading

${ }^{a}$ Key Laboratory for Organic Electronics and Information Displays, Jiangsu Key Laboratory for Biosensors, Institute of Advanced Materials (IAM), Nanjing University of Posts and Telecommunications (NUPT), Nanjing 210023, P. R. China. E-mail: iamqzhao@njupt.edu.cn

${ }^{b}$ Shaanxi Institute of Flexible Electronics (SIFE), Northwestern Polytechnical University (NPU), Xi'an 710072, Shaanxi, P. R. China. E-mail: provost@nwpu.edu.cn

$\dagger$ Electronic supplementary information (ESI) available. See DOI: $10.1039 / \mathrm{c} 9 \mathrm{sc} 03161 \mathrm{~h}$

$\$$ Authors contributed equally to this work. perfluorocarbon, intracellular hydrogen peroxide $\left(\mathrm{H}_{2} \mathrm{O}_{2}\right)$ catalytic catalase and manganese dioxide $\left(\mathrm{MnO}_{2}\right){ }^{23-32}$ Although the reported oxygen-generating materials have shown some promise, the amount of enriched oxygen is still difficult to improve because of the naturally limited effects and low endogenous $\mathrm{H}_{2} \mathrm{O}_{2}$ concentration. ${ }^{33,34}$ In this regard, it is highly desirable to design a new generation of anti-hypoxia nanocarriers with enhanced and self-sufficient oxygen supplementation.

Calcium peroxide $\left(\mathrm{CaO}_{2}\right)$ has been employed as a kind of oxygen-generating material. ${ }^{35}$ Different from other alkaline earth metal peroxides, it can slowly release oxygen in humid air and has been widely used in soil treatment and water disinfection. ${ }^{36-39}$ Inspired by this, $\mathrm{CaO}_{2}$ has recently been introduced as an implantable oxygen-generating material to overcome the hypoxia-induced restriction towards chemotherapy in cells and tissues. ${ }^{40}$ The self-sufficient oxygen supplementation made $\mathrm{CaO}_{2}$ a potential biomaterial that can synergistically work with a photosensitizing reagent and improve PDT efficiency, but the oversized structure suffered from limited penetration in the tumor tissue and the difficulty of clearance from the body. An alternative strategy has emerged to explore the small-sized $\mathrm{CaO}_{2}$ nanoparticles as oxygen-generating materials. ${ }^{41}$ However the slow and passive oxygen release from $\mathrm{CaO}_{2}$ nanoparticles compromised its efficacy after approaching the tumor tissues. Additionally, the gradually increased concentration of alkaline 
metabolites during oxygen generation results in potential longterm side effects on healthy tissues and organs.

Keeping the aforementioned issues in mind, herein, we proposed oxygen self-sufficient liposomes $\left(\mathrm{CaO}_{2} / \mathbf{B 1} / \mathrm{NH}_{4} \mathrm{HCO}_{3}\right.$ lipo), which consisted of hydrophobic halogenated aza-BODIPY dye (B1), oxygen-generating $\mathrm{CaO}_{2}$ nanoparticles, and hydrophilic thermoresponsive ammonium bicarbonate $\left(\mathrm{NH}_{4} \mathrm{HCO}_{3}\right)$ to regulate the hypoxic tumor microenvironment and overcome hypoxia-induced photodynamic resistance (Fig. 1a). In the liposomes, halogenated B1 was regarded as not only a potential photosensitizer through the preferable singlet-to-triplet transition but also a good organic photothermal agent because of strong near-infrared (NIR) absorption. ${ }^{\mathbf{4 2 , 4 3}}$ Under irradiation, B1 generated heat and triggered the decomposition of $\mathrm{NH}_{4} \mathrm{HCO}_{3}$, thereby resulting in the generation of $\mathrm{CO}_{2}$ bubbles. Thus, with the aid of $\mathbf{B 1}$ and $\mathrm{NH}_{4} \mathrm{HCO}_{3}, \mathrm{CaO}_{2}$ nanoparticles were induced to rapidly release oxygen by reaction with $\mathrm{CO}_{2}$. Additionally, the clean metabolite produced during the reaction reduced the toxicity to the body. Taking advantage of the enhanced selfsufficient oxygen, the hypoxia environment could be regulated and the photodynamic resistance in the tumors could be overcome. In in vivo environments, the liposomes were observed to accumulate in tumorous tissues through tail intravenous injection, which led to improved PDT efficiency under NIR irradiation. The relieved intratumoral hypoxia environment was demonstrated through immunofluorescence staining of hypoxia-associated proteins.

\section{Results and discussion}

In this work, we selected the polyethylene glycol (PEG) shelled liposome system as the nanocarrier owing to its good biocompatibility, enhanced tumor permeation and retention, and efficient loading capacity. The PEGylated liposomes included three elements, namely $\mathrm{CaO}_{2}$ nanoparticles, $\mathrm{NH}_{4} \mathrm{HCO}_{3}$ and halogenated aza-BODIPY (B1). $\mathrm{CaO}_{2}$ nanoparticles served as the resource of oxygen supplementation. The thermoresponsive

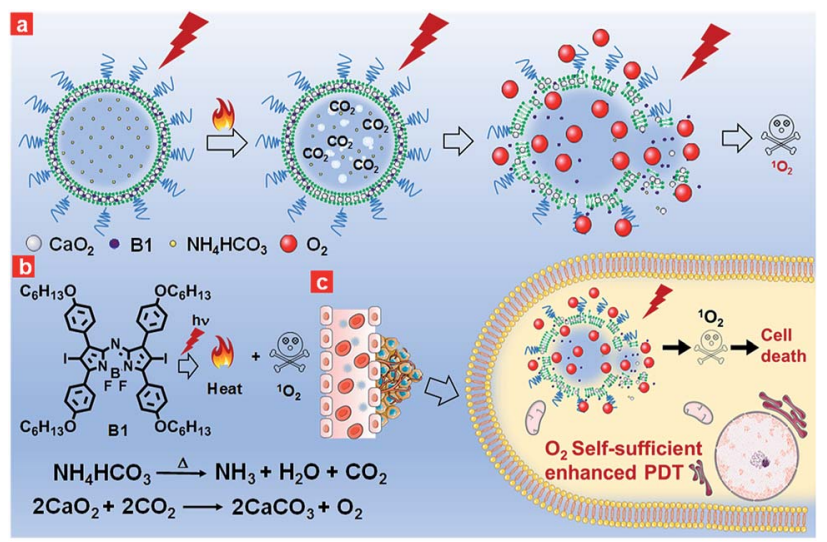

Fig. 1 (a) NIR-regulated generation of oxygen in $\mathrm{CaO}_{2} / \mathrm{B} 1 / \mathrm{NH}_{4} \mathrm{HCO}_{3}$ lipo and enhancement of ${ }^{1} \mathrm{O}_{2}$; (b) the mechanism of oxygen generation in $\mathrm{CaO}_{2} / \mathrm{B} 1 / \mathrm{NH}_{4} \mathrm{HCO}_{3}$ lipo; (c) in vivo the oxygen self-sufficient $\mathrm{CaO}_{2} / \mathrm{B1} / \mathrm{NH}_{4} \mathrm{HCO}_{3}$ lipo enhanced PDT and killed the cancer cells. molecule $\mathrm{NH}_{4} \mathrm{HCO}_{3}$, which can produce $\mathrm{CO}_{2}$ when temperature reaches $40{ }^{\circ} \mathrm{C},{ }^{\mathbf{4 4}}$ was employed as the stimulus to trigger the rapid release of oxygen from $\mathrm{CaO}_{2}$ nanoparticles. NIR dye $\mathbf{B 1}$ served as both a photothermal agent and a photosensitizer for PDT owing to the heavy atom effect. ${ }^{45}$

Firstly, $\mathrm{CaO}_{2}$ nanoparticles were prepared via the reaction of the calcium salt with $\mathrm{H}_{2} \mathrm{O}_{2}$ in the presence of ammonia. TEM images of $\mathrm{CaO}_{2}$ nanoparticles clearly showed a spherical structure and the average diameter was in the range of 5-15 nm (Fig. 2a). The dynamic light scattering (DLS) result revealed that $\mathrm{CaO}_{2}$ nanoparticles were well dispersed in aqueous solution and had an average diameter of $37.5 \mathrm{~nm}$ (Fig. S1a $\dagger$ ). The X-ray diffraction (XRD) pattern of the prepared $\mathrm{CaO}_{2}$ nanoparticles displayed the presence of peaks at $2 \theta=30.2^{\circ}, 35.6^{\circ}, 47.3^{\circ}, 51.6^{\circ}$, $53.1^{\circ}, 60.4^{\circ}$ (Fig. 2b), which were in accordance with the $2 \theta$ position of standard $\mathrm{CaO}_{2}$ (JCPDS 03-0865). Then hydrophobic B1 and $\mathrm{CaO}_{2}$ nanoparticles, together with hydrophilic $\mathrm{NH}_{4} \mathrm{HCO}_{3}$, were respectively encapsulated into the lipid bilayers and the aqueous cavity of the polyethylene glycol shelled liposomes through the lipid film hydration technique. $\mathrm{NH}_{4} \mathrm{HCO}_{3}$, $\mathrm{CaO}_{2} / \mathrm{NH}_{4} \mathrm{HCO}_{3}, \mathrm{CaO}_{2} / \mathrm{B1}$ and $\mathrm{CaO}_{2} / \mathrm{NH}_{4} \mathrm{HCO}_{3}$ lipo were also prepared as the control. The detailed synthetic procedures are described in the ESI. $\dagger$

Typically, $\mathrm{CaO}_{2} / \mathbf{B 1} / \mathrm{NH}_{4} \mathrm{HCO}_{3}$ lipo exhibited a spherical structure with a size of about $80 \mathrm{~nm}$ (Fig. 2c), which was optimized using different sonication powers (Fig. S2 $\dagger$ ). The DLS measurement gave a hydrodynamic size of $124.1 \mathrm{~nm}$ (Fig. S1b $\dagger$ ). The successful assembly of $\mathrm{CaO}_{2}$ nanoparticles was characterized by inductively coupled plasma-atomic emission spectrometry with a $37.0 \%$ weight ratio in the liposomes. Bands located at $765 \mathrm{~nm}$ and $823 \mathrm{~nm}$, respectively, in the absorption and photoluminescence spectra of $\mathrm{CaO}_{2} / \mathbf{B 1} / \mathrm{NH}_{4} \mathrm{HCO}_{3}$ lipo (Fig. S3a and $\mathrm{b}_{\dagger} \dagger$ ) were observed and could be ascribed to the $\mathbf{B 1}$ molecule. The NIR absorption and emission guaranteed that
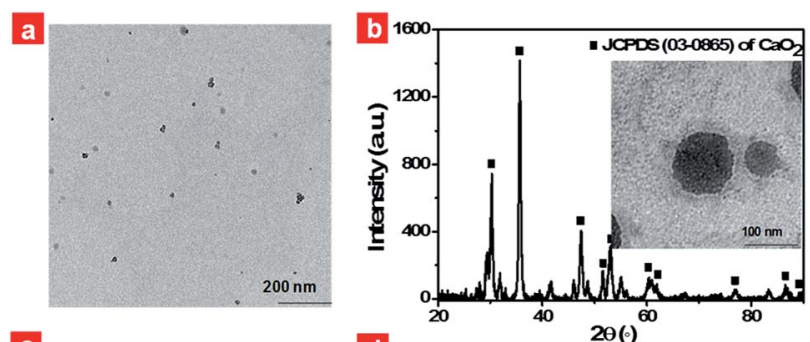

c
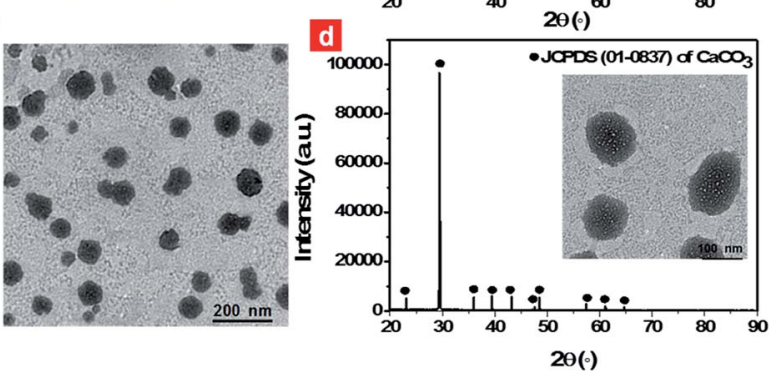

Fig. 2 TEM images of $\mathrm{CaO}_{2}$ nanoparticles (a) and $\mathrm{CaO}_{2} / \mathrm{B} 1 / \mathrm{NH}_{4} \mathrm{HCO}_{3}$ lipo (c); XRD patterns of $\mathrm{CaO}_{2} / \mathrm{B} 1 / \mathrm{NH}_{4} \mathrm{HCO}_{3}$ lipo before (b) and after heating to $45^{\circ} \mathrm{C}(\mathrm{d})$; insets show TEM images of $\mathrm{CaO}_{2} / \mathrm{B} 1 / \mathrm{NH}_{4} \mathrm{HCO}_{3}$ lipo before and after heating to $45^{\circ} \mathrm{C}$, respectively. 
the liposomes could be regarded as a potential imaging reagent in vivo. The loading weight of $\mathbf{B 1}$ in the liposomes was estimated to be $17.7 \%$. We fixed the amount of $\mathrm{CaO}_{2}$ nanoparticles and $\mathbf{B 1}$ in the lipid bilayers of the liposomes to balance the capacity for oxygen generation and photothermal effects. Additionally, bright-field images in the microscopy showed the formation of bubbles in the solution containing $\mathrm{NH}_{4} \mathrm{HCO}_{3}$ lipo at $45{ }^{\circ} \mathrm{C}$ (Fig. S4 $\dagger$ ), while no bubbles were observed at $37{ }^{\circ} \mathrm{C}$, suggesting that thermoresponsive $\mathrm{NH}_{4} \mathrm{HCO}_{3}$ was capable of well trapping in the liposome structure and underwent decomposition to produce $\mathrm{CO}_{2}$.

After successful incorporation of these elements into the displayed liposome structure, we clarified the reaction that occurred in $\mathrm{CaO}_{2} / \mathbf{B 1} / \mathrm{NH}_{4} \mathrm{HCO}_{3}$ lipo under local hyperthermia. The solution containing $\mathrm{CaO}_{2} / \mathbf{B 1} / \mathrm{NH}_{4} \mathrm{HCO}_{3}$ lipo was kept at $45{ }^{\circ} \mathrm{C}$ for $30 \mathrm{~min}$ and added dropwise onto a copper grid for TEM analysis. The Fig. $2 \mathrm{~b}$ inset displays the images of $\mathrm{CaO}_{2} / \mathbf{B 1} /$ $\mathrm{NH}_{4} \mathrm{HCO}_{3}$ lipo after heating. Small bubbles appeared on the surface of $\mathrm{CaO}_{2} / \mathbf{B 1} / \mathrm{NH}_{4} \mathrm{HCO}_{3}$ lipo. These liposomes were observed to swell and their diameters reached about $100 \mathrm{~nm}$. Additionally, the position of XRD peaks from $\mathrm{CaO}_{2} / \mathbf{B 1}$ / $\mathrm{NH}_{4} \mathrm{HCO}_{3}$ lipo under local hyperthermia corresponded to the standard $\mathrm{CaCO}_{3}$ (JCPDS 01-0837). The phenomenon suggested that the gas produced from the liposomes was originated from the reaction between $\mathrm{CaO}_{2}$ nanoparticles and $\mathrm{CO}_{2}$ from the decomposition of $\mathrm{NH}_{4} \mathrm{HCO}_{3}$.

Photothermal effects of the liposomes were the key factor to guarantee the rapid generation of oxygen. Thus we evaluated the photothermal effects of the prepared liposomes under $730 \mathrm{~nm}$ irradiation at $500 \mathrm{~mW} \mathrm{~cm}^{-2}$ through a thermal infrared imager (Fig. S5a $\dagger$ ). Liposomes containing B1 units were capable of elevating the solution temperature (Fig. 3a and b) when the irradiation time was prolonged, while liposomes in the absence of B1 units were not (Fig. S5b $\dagger$ ). The temperature elevation reached up to about $27.3{ }^{\circ} \mathrm{C}$ and $26.2{ }^{\circ} \mathrm{C}$ for $\mathrm{CaO}_{2} / \mathbf{B 1} / \mathrm{NH}_{4} \mathrm{HCO}_{3}$ lipo and $\mathrm{CaO}_{2} / \mathbf{B 1}$ lipo at a $\mathbf{B 1}$ loading concentration of $40 \mu \mathrm{M}$, respectively, after the irradiation time reached $300 \mathrm{~s}$, indicating that B1 played an effective role in the photothermal effects.

To demonstrate our hypothesis about the rapid and enhanced oxygen generation of $\mathrm{CaO}_{2} / \mathbf{B 1} / \mathrm{NH}_{4} \mathrm{HCO}_{3}$ lipo through photothermal effects, the oxygen generation was tested through a portable dissolved oxygen meter (Fig. 3c). Without irradiation, the concentration of oxygen released from $\mathrm{CaO}_{2} / \mathbf{B 1} /$ $\mathrm{NH}_{4} \mathrm{HCO}_{3}, \mathrm{CaO}_{2} / \mathrm{NH}_{4} \mathrm{HCO}_{3}$ and $\mathrm{CaO}_{2} / \mathbf{B 1}$ lipo was observed to slowly increase for $20 \mathrm{~min}$. As expected, irradiation $(730 \mathrm{~nm}, 500$ $\mathrm{mW} \mathrm{cm}{ }^{-2}$ ) triggered the rapid generation of oxygen in the buffer solution containing $\mathrm{CaO}_{2} / \mathbf{B 1} / \mathrm{NH}_{4} \mathrm{HCO}_{3}$ lipo. Compared to $\mathrm{CaO}_{2} / \mathbf{B 1} / \mathrm{NH}_{4} \mathrm{HCO}_{3}$ lipo, $\mathrm{CaO}_{2} / \mathrm{NH}_{4} \mathrm{HCO}_{3}$ lipo and $\mathrm{CaO}_{2} / \mathbf{B 1}$ lipo exhibited a relatively small amount of oxygen generation, which was attributed to the sustained hydrolysis of $\mathrm{CaO}_{2}$ nanoparticles. These results demonstrated that $\mathrm{CaO}_{2}$ nanoparticles in the liposomes efficiently and rapidly supplied oxygen with the aid of photothermal effects from $\mathbf{B 1}$ and thermal reaction from $\mathrm{NH}_{4} \mathrm{HCO}_{3}$. Additionally, the $\mathrm{pH}$ values of the aqueous solution, which contained $\mathrm{CaO}_{2} / \mathbf{B 1} / \mathrm{NH}_{4} \mathrm{HCO}_{3}$ lipo with different concentrations, were examined to range between 7.1 and 8.3 under irradiation for $20 \mathrm{~min}$ (Fig. S6†), indicating small effects of metabolites on $\mathrm{pH}$ values. The slight increase of the initial $\mathrm{pH}$ in the solution containing the concentrated liposomes could be ascribed to the increased opportunity of reaction between $\mathrm{CaO}_{2}$ nanoparticles and water.
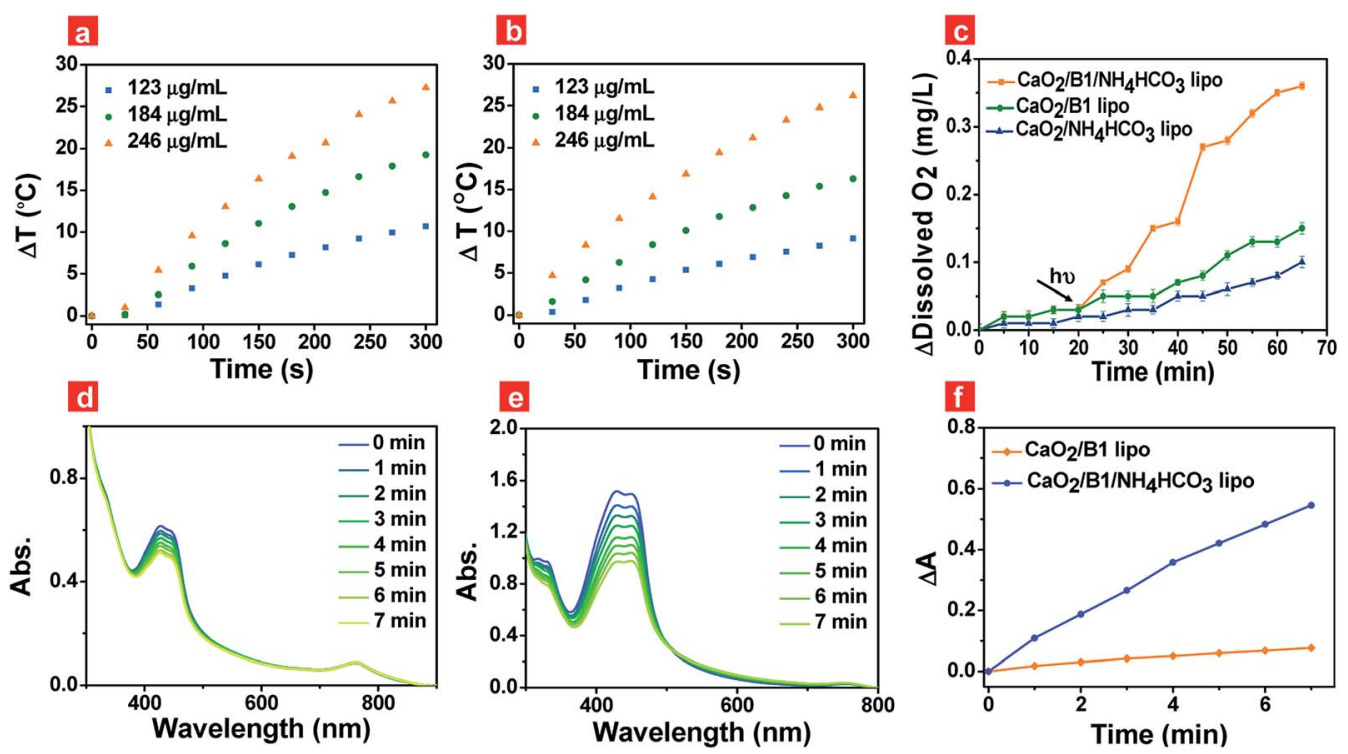

Fig. 3 Temperature changes of $\mathrm{CaO}_{2} / \mathrm{B} 1$ lipo (a) and $\mathrm{CaO}_{2} / \mathrm{B} 1 / \mathrm{NH}_{4} \mathrm{HCO}_{3}$ lipo (b) at a $\mathrm{B} 1$ concentration of 20,30 and $40 \mu \mathrm{M}$ under different irradiation times; (c) oxygen generation of $\mathrm{CaO}_{2} / \mathrm{B} 1$ lipo, $\mathrm{CaO}_{2} / \mathrm{B} 1 / \mathrm{NH}_{4} \mathrm{HCO}_{3}$ lipo and $\mathrm{CaO}_{2} / \mathrm{NH}_{4} \mathrm{HCO}_{3}$ lipo $(184 \mu \mathrm{g} \mathrm{mL}$ ) without and with irradiation; absorption spectra of a mixture containing DPBF and $\mathrm{CaO}_{2} / \mathrm{B} 1$ lipo (d), $\mathrm{CaO}_{2} / \mathrm{B} 1 / \mathrm{NH}_{4} \mathrm{HCO}_{3}$ lipo (e) $\left(184 \mu \mathrm{g} \mathrm{mL}{ }^{-1}\right)$ at different irradiation times in the hypoxia environment. (f) $\Delta A$ of DPBF at $427 \mathrm{~nm}$ which is obtained from figures (d) and (e). $\Delta A=A_{t}-A_{0}$, where $A_{t}$ is the absorbance of DPBF at $427 \mathrm{~nm}$ at different illumination times and $A_{0}$ is the absorption without irradiation. The excitation wavelength of irradiation is $730 \mathrm{~nm}$. The power density is $500 \mathrm{~mW} \mathrm{~cm}^{-2}$. 
To pave the way for the utilization of $\mathrm{CaO}_{2} / \mathbf{B 1} / \mathrm{NH}_{4} \mathrm{HCO}_{3}$ lipo in hypoxic PDT, the light-induced ${ }^{1} \mathrm{O}_{2}$ release was assessed using 1,3-diphenylisobenzofuran (DPBF), a ${ }^{1} \mathrm{O}_{2}$ indicator, in air and the hypoxia environment that was built by bubbling with nitrogen gas. ROS generation experiments were performed at $37{ }^{\circ} \mathrm{C}$ to imitate the in vivo environment. In air, a decreased absorbance of DPBF at $427 \mathrm{~nm}$ was observed in the liposome containing B1 units under irradiation (Fig. S7a and b $\dagger$ ), suggesting that $\mathbf{B 1}$ served as a photosensitizer to release ${ }^{1} \mathrm{O}_{2}$ through the preferable singlet-to-triplet transition. Rapid ${ }^{1} \mathrm{O}_{2}$ generation was observed in the group of $\mathrm{CaO}_{2} / \mathbf{B 1} / \mathrm{NH}_{4} \mathrm{HCO}_{3}$ lipo (Fig. S7c $\dagger$ ), indicative of the important role of the oxygen supplement from the reaction between $\mathrm{CaO}_{2}$ nanoparticles and $\mathrm{NH}_{4} \mathrm{HCO}_{3}$. The light-induced oxygen supplementation enhanced the probability of energy transfer between excited $\mathbf{B 1}$ and oxygen, leading to an increased amount of ${ }^{1} \mathrm{O}_{2}$ released. In the hypoxia environment, ${ }^{1} \mathrm{O}_{2}$ release was largely limited from $\mathrm{CaO}_{2} / \mathbf{B 1}$ lipo (Fig. 3d), while ${ }^{1} \mathrm{O}_{2}$ was observed to be more efficiently and rapidly released from $\mathrm{CaO}_{2} / \mathbf{B 1} / \mathrm{NH}_{4} \mathrm{HCO}_{3}$ lipo
(Fig. 3e). The absorbance changes illustrated in Fig. $3 \mathrm{f}$ displayed the enhanced amount of ${ }^{1} \mathrm{O}_{2}$ released in the hypoxia environment. The results showed the potential utilization of $\mathrm{CaO}_{2} / \mathbf{B 1} /$ $\mathrm{NH}_{4} \mathrm{HCO}_{3}$ lipo in the hypoxia environment.

The capacity of the liposomes to overcome the hypoxiaassociated resistance towards PDT was examined in vitro using HeLa cells as a model through confocal laser-scanning luminescence microscopy. Light-induced intracellular generation of reactive oxygen species was assessed using 2,7-dichlorofluorescein diacetate (DCFH-DA) as an indicator. As illustrated in Fig. 4a, intracellular green fluorescence was observed in $\mathrm{CaO}_{2} / \mathbf{B 1}$ lipo and $\mathrm{CaO}_{2} / \mathbf{B 1} / \mathrm{NH}_{4} \mathrm{HCO}_{3}$ lipo treated cells under irradiation for $5 \mathrm{~min}$ in air owing to the presence of photosensitizer B1 units in the liposomes. However in the hypoxia environment, relatively intense fluorescence was detected in $\mathrm{CaO}_{2} / \mathbf{B 1} / \mathrm{NH}_{4} \mathrm{HCO}_{3}$ lipo treated cells compared to $\mathrm{CaO}_{2} / \mathbf{B 1}$ lipo treated cells, which demonstrated that the good ability of the light-triggered oxygen production would be beneficial to ${ }^{1} \mathrm{O}_{2}$ generation from $\mathbf{B 1}$ in the intracellular hypoxia environment. As

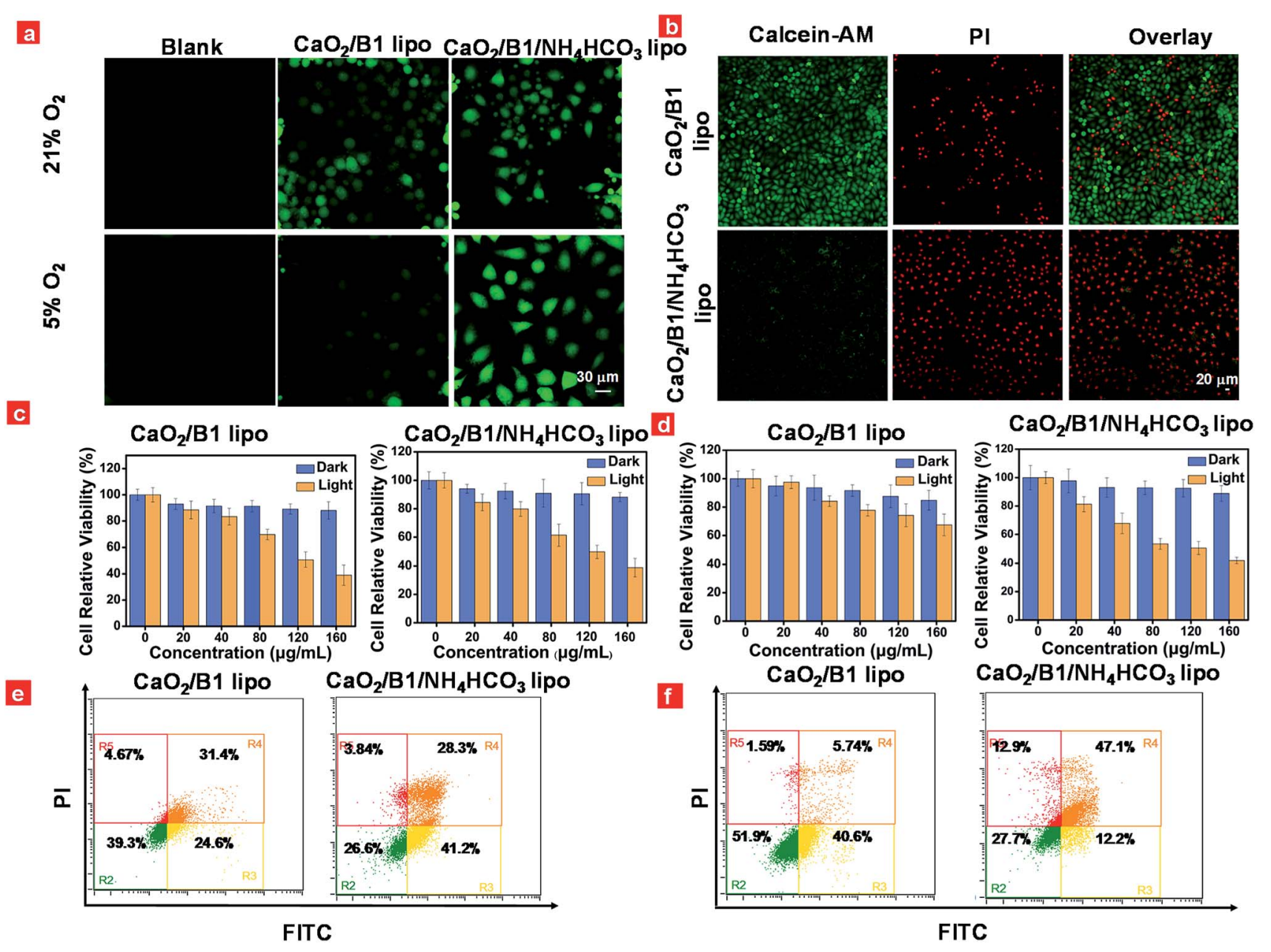

Fig. 4 (a) ROS generation in cells incubated with $\mathrm{CaO}_{2} / \mathrm{B} 1$ lipo and $\mathrm{CaO}_{2} / \mathrm{B} 1 / \mathrm{NH}_{4} \mathrm{HCO}_{3}$ lipo $\left(80 \mu \mathrm{g} \mathrm{mL} \mathrm{m}^{-1}\right)$ under $21 \%$ and $5 \%$ oxygen levels and then exposed to irradiation; (b) calcein-AM/PI staining of cells incubated with $\mathrm{CaO}_{2} / \mathrm{B} 1$ lipo and $\mathrm{CaO}_{2} / \mathrm{B} / \mathrm{NH}_{4} \mathrm{HCO}_{3}$ lipo $\left(80 \mu \mathrm{g} \mathrm{mL}{ }^{-1}\right) \mathrm{under}$ a $5 \%$ oxygen level and then exposed to irradiation; MTT assays of cells incubated with $\mathrm{CaO}_{2} / \mathrm{B} 1$ lipo and $\mathrm{CaO} / \mathrm{B} 1 / \mathrm{NH}_{4} \mathrm{HCO} 3$ lipo $\left(80 \mu \mathrm{mL} \mathrm{H}^{-1}\right)$ under $21 \%$ (c) and $5 \%$ (d) oxygen levels and then exposed to irradiation; flow cytometry results of cells incubated with $\mathrm{CaO}_{2} / \mathrm{B} 1$ lipo and $\mathrm{CaO} / \mathrm{B} 1 /$ $\mathrm{NH}_{4} \mathrm{HCO}_{3}$ lipo $\left(80 \mu \mathrm{g} \mathrm{mL}^{-1}\right)$ under $21 \%$ (e) and $5 \%$ (f) oxygen levels and then treated with Annexin $\mathrm{V}$-FITC/PI under irradiation. The excitation wavelength of irradiation is $730 \mathrm{~nm}$. The power density is $500 \mathrm{~mW} \mathrm{~cm}^{-2}$. The irradiation time is $5 \mathrm{~min}$. 
a control, blank cells or cells incubated with $\mathrm{NH}_{4} \mathrm{HCO}_{3}$ lipo and $\mathrm{CaO}_{2} / \mathrm{NH}_{4} \mathrm{HCO}_{3}$ lipo showed weak fluorescence under light stimulation in air and in the hypoxia environment (Fig. S8†).

Furthermore, the anticancer efficiency was investigated through calcine $\mathrm{AM}$ and propidium iodide (PI) co-staining assay. Different from the control groups containing blank cells or cells incubated with $\mathrm{NH}_{4} \mathrm{HCO}_{3}$ lipo and $\mathrm{CaO}_{2} / \mathrm{NH}_{4} \mathrm{HCO}_{3}$ lipo, cells treated with $\mathrm{CaO}_{2} / \mathbf{B 1}$ lipo and $\mathrm{CaO}_{2} / \mathbf{B 1} / \mathrm{NH}_{4} \mathrm{HCO}_{3}$ lipo were totally damaged and displayed an intense red fluorescence signal from PI, while the green fluorescence from calcine AM was hardly observed in air (Fig. S9†). Notably, in the hypoxia environment, the damage effects of the cells incubated with $\mathrm{CaO}_{2} / \mathbf{B 1}$ lipo were limited owing to insufficient oxygen supplementation (Fig. 4b). The cells incubated with $\mathrm{CaO}_{2} / \mathbf{B 1} /$ $\mathrm{NH}_{4} \mathrm{HCO}_{3}$ lipo showed good anticancer efficiency after irradiation in the hypoxia environment. To determine whether the anticancer efficiency was attributed to the photothermal effect from B1 units, cells preincubated with NAC, a ROS scavenger, and $\mathrm{CaO}_{2} / \mathbf{B} \mathbf{B} / \mathrm{NH}_{4} \mathrm{HCO}_{3}$ lipo were investigated after irradiation in air and the hypoxia environment (Fig. S11 $\dagger$ ). Only a green fluorescence signal was detected in the cells, revealing that the PDT effect was dominated to induce the cell death.

Consequently, the phototoxicity of the liposomes towards HeLa cells was assessed through the methyl thiazalyltetrazalium (MTT) assay. As illustrated in Fig. 4c and d, liposomes with different concentrations were added to the medium of cells. When the cells were incubated in the dark for $24 \mathrm{~h}$, the liposomes treated cells sustained high cell viability $(>80 \%)$ when the dose was less than $160 \mu \mathrm{g} \mathrm{mL} \mathrm{m}^{-1}$, demonstrating the low cytotoxicity of these liposomes towards HeLa cells. After irradiation, about $38.9 \%$ and $38.8 \%$ cell viability were observed when the cells were treated with $\mathrm{CaO}_{2} / \mathbf{B} \mathbf{1}$ lipo and $\mathrm{CaO}_{2} / \mathbf{B} \mathbf{B} / \mathrm{NH}_{4} \mathrm{HCO}_{3}$ lipo, respectively at a concentration of $160 \mu \mathrm{g} \mathrm{mL}^{-1}$ in air (Fig. 4c), whereas in the hypoxia environment the values changed to $67.5 \%$ and $41.9 \%$ at the same concentration, respectively (Fig. $4 \mathrm{~d}$ ). The control groups, including cells incubated with $\mathrm{NH}_{4} \mathrm{HCO}_{3}$ lipo and $\mathrm{CaO}_{2} /$ $\mathrm{NH}_{4} \mathrm{HCO}_{3}$ lipo, maintained good cell viability (>73\%) in the absence and presence of irradiation (Fig. S12 $\dagger$ ). On the other hand, flow cytometry experiments by FITC and PI co-staining were conducted. In agreement with the above MTT assay, the percentage of late apoptotic cells treated with $\mathrm{CaO}_{2} / \mathbf{B 1} / \mathrm{NH}_{4} \mathrm{HCO}_{3}$ lipo reached $28.3 \%$ and $47.1 \%$ in air and the hypoxia environment, respectively (Fig. 4e and f), suggesting the good anticancer capacity of the oxygen self-sufficient $\mathrm{CaO}_{2} / \mathbf{B} \mathbf{1} / \mathrm{NH}_{4} \mathrm{HCO}_{3}$ lipo. Compared to other control groups, better anticancer capacity of $\mathrm{CaO}_{2} / \mathbf{B} \mathbf{1} / \mathrm{NH}_{4} \mathrm{HCO}_{3}$ lipo was observed in the hypoxia environment (Fig. 4f, S13 and S14†). All the results demonstrated that the light-amplified oxygen supplementation in $\mathrm{CaO}_{2} / \mathbf{B} \mathbf{1} / \mathrm{NH}_{4} \mathrm{HCO}_{3}$ lipo would be favorable to overcome the hypoxia-associated restriction towards PDT.

Encouraged by the intracellular results, we further verified the in vivo PDT effects of liposomes and examined the intratumoral anti-hypoxia capacity. HeLa tumor-bearing nude mice were employed as the model. $\mathrm{CaO}_{2} / \mathbf{B} \mathbf{1} / \mathrm{NH}_{4} \mathrm{HCO}_{3}$ lipo were intravenously injected into the mice and the biodistribution of the liposomes was tracked at $1 \mathrm{~h}, 2 \mathrm{~h}, 4 \mathrm{~h}, 12 \mathrm{~h}$, and $24 \mathrm{~h}$ postinjection. Enhanced fluorescence in the tumor was exhibited at
$1 \mathrm{~h}$ post-injection (Fig. 5a), revealing the significant accumulation of $\mathrm{CaO}_{2} / \mathbf{B 1} / \mathrm{NH}_{4} \mathrm{HCO}_{3}$ lipo there, which can be attributed to the enhanced permeability and retention effects. The fluorescence intensity reached a plateau at $4 \mathrm{~h}$ post-injection, and the tumorous fluorescence could be detected at $24 \mathrm{~h}$ post-injection. The fluorescence gradually decreased with the time prolonging owing to the metabolism of $\mathrm{CaO}_{2} / \mathbf{B} 1 / \mathrm{NH}_{4} \mathrm{HCO}_{3}$ lipo (Fig. S15 $\dagger$ ). Compared to other major organs, the tumor exhibited the maximized biodistribution, supporting the fact that $\mathrm{CaO}_{2} / \mathbf{B 1} /$ $\mathrm{NH}_{4} \mathrm{HCO}_{3}$ lipo exhibited good accumulation in the tumor (Fig. S16†).

Prior to the evaluation of anticancer efficiency in vivo, we first analysed the photothermal effects using 4 groups of tumorbearing mice (Fig. 5b). After $4 \mathrm{~h}$ injection, the temperature of the tumor region was monitored under $730 \mathrm{~nm}$ laser irradiation $\left(100 \mathrm{~mW} \mathrm{~cm}^{-2}\right)$. No matter whether NAC was injected into the mice, mice treated with $\mathrm{CaO}_{2} / \mathbf{B} \mathbf{1} / \mathrm{NH}_{4} \mathrm{HCO}_{3}$ lipo and $\mathrm{CaO}_{2} / \mathbf{B 1}$ lipo showed that the temperature of the tumor region reached up to about $45{ }^{\circ} \mathrm{C}$ (Fig. $5 \mathrm{~b}$ and $\mathrm{S} 17 \dagger$ ). In the control group of PBStreated mice, little temperature enhancement $\left(0.46^{\circ} \mathrm{C}\right)$ was observed. According to the temperature mapping results, the temperature of the tumor-surrounding region was not obviously affected by the irradiation. These results revealed that the good photothermal effects of liposomes containing B1 played a key role in increasing the temperature in the tumor region and had no obvious damage to the surrounding tissues. To mainly

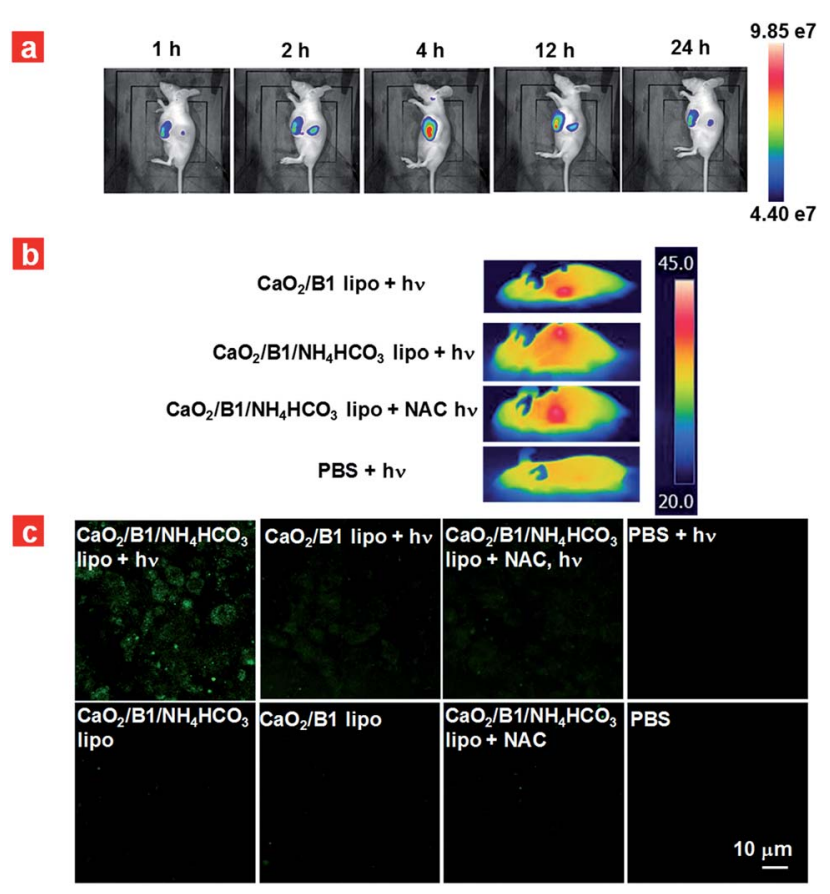

Fig. 5 (a) Fluorescence images of a mouse bearing tumors monitored after tail intravenous injection of $\mathrm{CaO}_{2} / \mathrm{B} 1 / \mathrm{NH}_{4} \mathrm{HCO}_{3}$ lipo $(800 \mu \mathrm{g}$ $\mathrm{mL}^{-1}$ ) at different times; (b) photothermal images of the mice bearing tumors with different treatments under irradiation $(730 \mathrm{~nm}, 100 \mathrm{~mW}$ $\mathrm{cm}^{-2}$ ); (c) ROS generation of a tumor slice obtained from the mice with different treatments. " $+h \nu$ " represents that the slice was from the mice exposed to irradiation $\left(730 \mathrm{~nm}, 100 \mathrm{~mW} \mathrm{~cm}^{-2}\right.$ ). NAC represents that it was pre-injected into the mice to scavenge ROS. 
investigate the photodynamic performance in vivo, we further exposed the mice under irradiation $\left(730 \mathrm{~nm}, 100 \mathrm{~mW} \mathrm{~cm}^{-2}\right)$ for $5 \mathrm{~min}$ for therapy to avoid the overheating of the tumor. The ROS generation of tumor slices was investigated using DCHFDA as the indicator (Fig. 5c). The confocal image of slices from $\mathrm{CaO}_{2} / \mathbf{B 1} / \mathrm{NH}_{4} \mathrm{HCO}_{3}$ lipo injected mice exhibited a relatively more intense fluorescence signal compared to that from $\mathrm{CaO}_{2} / \mathbf{B 1}$ lipo injected mice, indicating more ROS generation in the group of $\mathrm{CaO}_{2} / \mathbf{B 1} / \mathrm{NH}_{4} \mathrm{HCO}_{3}$ lipo. The phenomenon could be ascribed to the light-triggered photodynamic efficiency because the groups without irradiation or with NAC treatment displayed weak fluorescence.

Inspired by the results of photothermal effects and ROS generation in vivo, we further estimated the regression degree of tumor growth to evaluate the anticancer efficiency of $\mathrm{CaO}_{2} / \mathbf{B 1} /$ $\mathrm{NH}_{4} \mathrm{HCO}_{3}$ lipo. Mice that bear tumors were intravenously injected with different samples, followed by irradiation for 5 min or not. The body weight and tumor volume were monitored every 2 days. The body weight of the mice sustained between 16 and $19 \mathrm{~g}$ (Fig. 6a), and no abnormal behaviors were observed during therapy. Without irradiation, all groups showed rapid and similar enhancement of tumor volume and about a 20-fold increase was detected after 14 day treatment (Fig. 6b and c), suggesting the negligible effects of samples on tumor growth. When tumors were subjected to irradiation, the group of $\mathrm{CaO}_{2} / \mathbf{B 1} / \mathrm{NH}_{4} \mathrm{HCO}_{3}$ lipo inhibited tumor growth and induced tumor disappearance after 14 days although an obvious scar was found on the mice treated with $\mathrm{CaO}_{2} / \mathbf{B 1}$ / $\mathrm{NH}_{4} \mathrm{HCO}_{3}$ lipo after 4 days, while the tumor volumes of the group treated with $\mathrm{CaO}_{2} / \mathbf{B 1}$ lipo were observed to increase 4.7 fold. These results revealed that enough oxygen generation from $\mathrm{CaO}_{2} / \mathbf{B 1} / \mathrm{NH}_{4} \mathrm{HCO}_{3}$ lipo was favorable to produce ${ }^{1} \mathrm{O}_{2}$ in the presence of photosensitizer $\mathbf{B 1}$, thus resulting in an irreversible oxidative injury in tumors. When $\mathrm{CaO}_{2} / \mathbf{B 1} / \mathrm{NH}_{4} \mathrm{HCO}_{3}$ lipotreated mice were injected with NAC ahead of irradiation, the tumor growth remained, demonstrating limited photothermal effects on tumor growth owing to the low power density of laser irradiation. The associated photographs of mice treated with different samples and tumors are illustrated in Fig. S18. $\dagger$

To corroborate the therapeutic efficiency of liposomes, we collected the slices of tumors and major organs at the end of treatment, which were investigated by hematoxylin \& eosin (H\&E) staining (Fig. 6d). With irradiation, cell damage and inflammatory lesion were found in the tumors of $\mathrm{CaO}_{2} / \mathbf{B 1}$ / $\mathrm{NH}_{4} \mathrm{HCO}_{3}$ lipo-treated mice. The group treated with NAC also displayed tumor necrosis to some degree due to photothermal effects. However the morphology of tumor slices from the groups without irradiation was not affected, demonstrating the importance of irradiation for anticancer therapy. Major organs sliced after treatment displayed negligible pathological changes (Fig. S19†). Taken all the results in vivo together, oxygen selfsufficient $\mathrm{CaO}_{2} / \mathbf{B 1} / \mathrm{NH}_{4} \mathrm{HCO}_{3}$ lipo induced the dominated
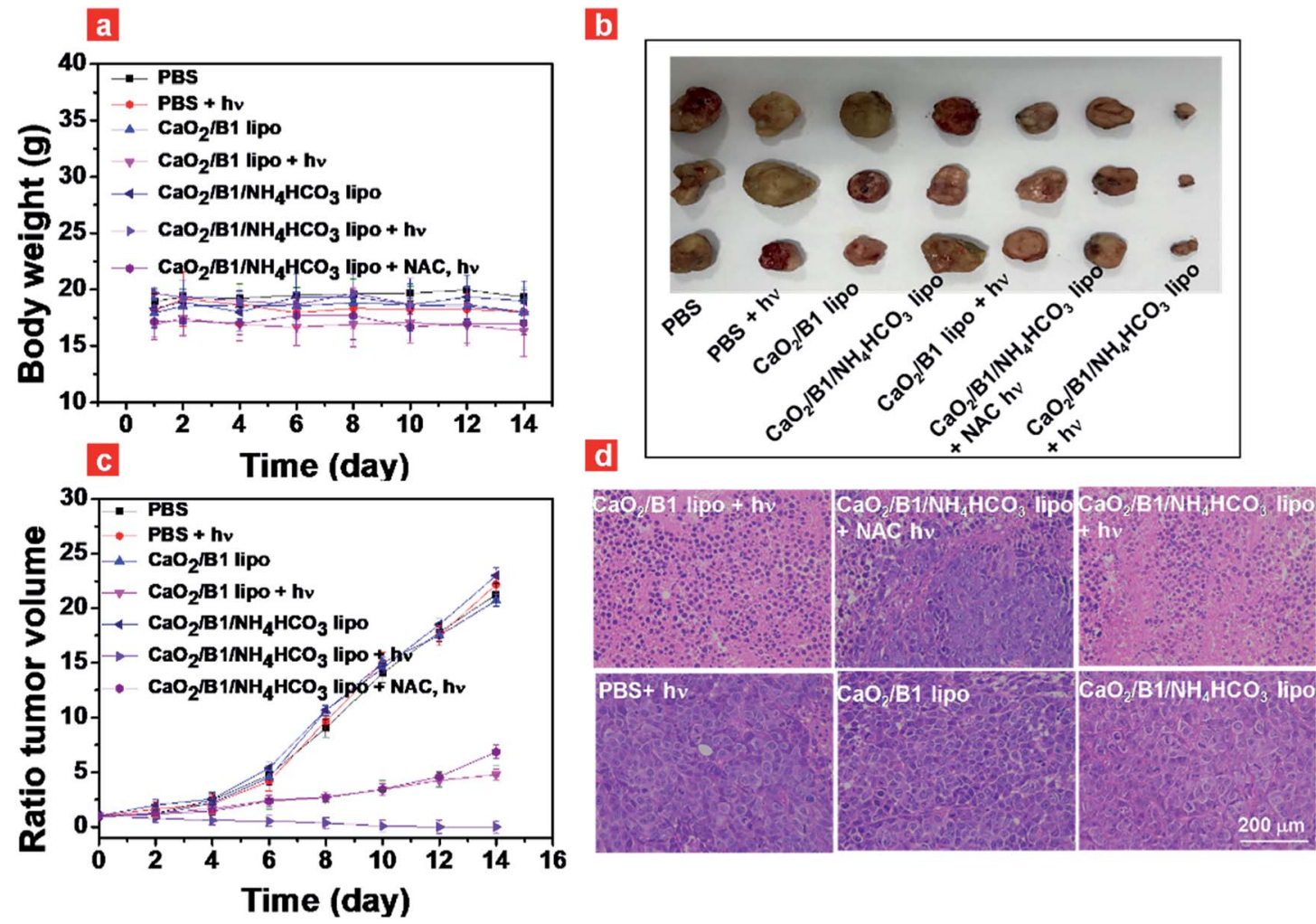

Fig. 6 (a) Body weight of mice with different treatments during the therapy process; (b) photograph of tumors obtained from the mice after 14 days; (c) tumor volume ratio of mice that underwent different treatments during the therapy process; (d) H\&E staining of tumor slices obtained from the different groups of mice after 14 days. " $+h \nu^{\prime}$ represents that the slice was from the mice exposed to irradiation (730 nm, $100 \mathrm{~mW} \mathrm{~cm}^{-2}$ ). NAC represents that it was pre-injected into the mice to scavenge ROS. 
oxidative damage towards tumors under irradiation. What's more, the resistance of the intratumoral hypoxia environment was examined through immunofluorescence staining of the hypoxia inducible factor (HIF-1 $\alpha$ ) and carbonic anhydrase IX (CA9) (Fig. S20 $\dagger$ ). The tumor sliced from $\mathrm{CaO}_{2} / \mathbf{B 1} / \mathrm{NH}_{4} \mathrm{HCO}_{3}$ lipo-treated mice exhibited lower expression of HIF- $1 \alpha$ and CA9 compared to the group of $\mathrm{CaO}_{2} / \mathbf{B 1}$ lipo, which indicated that the light-triggered $\mathrm{CaO}_{2} / \mathbf{B 1} / \mathrm{NH}_{4} \mathrm{HCO}_{3}$ lipo could relieve the intratumoral hypoxia environment.

\section{Conclusions}

In summary, we have exhibited a proof-of-concept study that $\mathrm{CaO}_{2} / \mathbf{B 1} / \mathrm{NH}_{4} \mathrm{HCO}_{3}$ lipo can be employed as an oxygen selfsufficient nanomaterial to overcome hypoxia-associated restriction towards PDT. Under irradiation, the liposomes selfsufficiently triggered oxygen generation accompanied by clean by-products. Furthermore, the light-triggered oxygen supplementation favoured enhanced ${ }^{1} \mathrm{O}_{2}$ generation in the presence of the photosensitizer (B1), thus resulting in improved anticancer efficiency. In the context of good therapy effects in vitro, we estimated the administration of intravenous injection of the liposomes in mice. The liposomes were accumulated in the tumor after $4 \mathrm{~h}$ injection. The relief of the hypoxia environment in vivo was observed through immunofluorescence staining of HIF- $1 \alpha$ and CA9. The enhanced ${ }^{1} \mathrm{O}_{2}$ generation induced an oxidative damage towards the tumor, and further led to a good inhibitory effect on the tumor growth. In this work, the utilization of the light-activatable oxygen self-sufficient $\mathrm{CaO}_{2} / \mathbf{B 1}$ / $\mathrm{NH}_{4} \mathrm{HCO}_{3}$ lipo offers a valuable attempt to regulate intratumoral hypoxia and overcome the limitation of current PDT. To our knowledge, this highlights the first example of using NIR light to activate $\mathrm{CaO}_{2}$ nanoparticle-containing liposomes for the modulation of the hypoxic environment in tumors.

\section{Experimental section}

The detailed information of materials, instruments, synthesis and characterization of liposomes, cell culture, and in vitro/in vivo experiments can be found in the ESI. $\dagger$

\section{Animal models}

All the nude mice were purchased from the Comparative Medicine Center of Yangzhou University. All the animal experiments were conducted in line with the specifications of The National Regulation of China for Care and Use of Laboratory Animals and approved by the Jiangsu Administration of Experimental Animals.

\section{Conflicts of interest}

There are no conflicts to declare.

\section{Acknowledgements}

We gratefully acknowledge the financial support from the National Natural Science Foundation of China (Grant No. 61805122), the National Funds for Distinguished Young Scientists (61825503), and the National Program for Support of TopNotch Young Professionals.

\section{Notes and references}

1 Q. Chang, I. Jurisica, T. Do and D. W. Hedley, Cancer Res., 2011, 71, 3110.

2 R. A. Cairns, I. S. Harris and T. W. Mak, Nat. Rev. Cancer, 2011, 11, 85.

3 W. R. Wilson and M. P. Hay, Nat. Rev., 2011, 11, 393.

4 J. Liu, W. Bu and J. Shi, Chem. Rev., 2017, 117, 6160.

5 A. L. Harris, Nat. Rev. Cancer, 2002, 2, 38.

6 D. F. Quail and J. A. Joyce, Nat. Med., 2013, 19, 1423.

7 R. Jahanban-Esfahlan, M. de la Guardia, D. Ahmadi and B. Yousefi, J. Cell. Physiol., 2018, 233, 2019.

8 A. I. Minchinton and I. F. Tannock, Nat. Rev. Cancer, 2006, 6, 583.

9 T. Maleki, N. Cao, S. Song, C. Kao, S. Ko and B. Ziaie, IEEE Trans. Biomed. Eng., 2007, 58, 3104.

10 Q. Hu, W. Sun, Y. Lu, H. N. Bomba, Y. Ye, T. Jiang, A. J. Isaacson and Z. Gu, Nano Lett., 2016, 16, 1118.

11 R. Cairns, I. Papandreous and N. Denko, Mol. Cancer Res., 2006, 4, 61.

12 X. Li, N. Kwon, T. Guo, Z. Liu and J. Yoon, Angew. Chem., Int. Ed., 2018, 57, 11522.

13 W. Fan, P. Huang and X. Chen, Chem. Soc. Rev., 2016, 45, 6488.

14 Z. Zou, J. Song, L. Nie and X. Chen, Chem. Soc. Rev., 2016, 45, 6597.

15 Y. Shen, A. J. Shuhendler, D. Ye, J.-J. Xu and H.-Y. Chen, Chem. Soc. Rev., 2016, 45, 6725.

16 X. Li, S. Lee and J. Yoon, Chem. Soc. Rev., 2018, 47, 1174.

17 S. S. Lucky, K. C. Soo and Y. Zhang, Chem. Rev., 2015, 115, 1990.

18 Y. Liu, X. Meng and W. Bu, Coord. Chem. Rev., 2019, 379, 82. 19 J. Li and K. Pu, Chem. Soc. Rev., 2019, 48, 38.

20 S. Monro, K. L. Colon, H. Yin, J. Roque, P. Konda, S. Gujar, R. P. Thummel, L. Lilge, C. G. Cameron and S. A. McFarland, Chem. Rev., 2019, 119, 797.

21 W. Zhu, Z. Dong, T. Fu, J. Liu, Q. Chen, Y. Li, R. Zhu, L. Xu and Z. Liu, Adv. Funct. Mater., 2016, 26, 5490.

22 C. Jin, J. Lovel, J. Chen and G. Zhang, ACS Nano, 2013, 7, 2541.

23 H. Ren, J. Liu, F. Su, S. Ge, A. Yuan, W. Dai, J. Wu and Y. Hu, ACS Appl. Mater. Interfaces, 2017, 9, 3463.

24 H. Chen, J. Tian, W. He and Z. Guo, J. Am. Chem. Soc., 2015, 137, 1539.

25 D. He, L. Hai, X. He, X. Yang and H.-W. Li, Adv. Funct. Mater., 2017, 27, 1704089.

26 G. Yang, L. Xu, Y. Chao, J. Xu, X. Sun, Y. Wu, R. Peng and Z. Liu, Nat. Commun., 2017, 8, 902. 
27 M. Song, T. Liu, C. Shi, X. Zhang and X. Chen, ACS Nano, 2016, 10, 633.

28 C. Liu, D. Wang, S. Zhang, Y. Cheng, F. Yang, Y. Xing, T. Xu, H. Dong and X. Zhang, ACS Nano, 2019, 13, 4267.

29 Y. Yang, C. Wang, C. Tian, H. Guo, Y. Shen and M. Zhu, J. Mater. Chem. B, 2018, 6, 6848.

30 D. Hu, L. Zhong, M. Wang, H. Li, Y. Qu, Q. Liu, R. Han, L. Yuan, K. Shi and J. Peng, Adv. Funct. Mater., 2019, 29, 1806199.

31 M. Yu, X. Xu, Y. Cai, L. Zou and X. Shuai, Biomaterials, 2018, 175, 61.

32 Q. Jia, J. Ge, W. Liu, X. Zheng, S. Chen, Y. Wen, H. Zhang and Y. Wang, Adv. Mater., 2018, 30, 1706090.

33 D.-W. Zheng, B. Li, C.-X. Li, J.-X. Fan, Q. Lei, C. Li, Z. Xu and X.-Z. Zhang, ACS Nano, 2016, 10, 8715.

34 R. H. Cool, E. Merten, C. Theiss and H. Acker, Biochem. J., 1998, 332, 5.

35 A. Rastinfard, M. H. Nazarpak and F. Moztarzadeh, RSC Adv., 2018, 9, 91.

36 B. W. Bogan, V. Trbovic and J. R. Paterek, Chemosphere, 2003, 50, 12.
37 A. C. Ndjou'ou and D. P. Cassidy, Chemosphere, 2006, 65, 1610.

38 Y. Qian, X. Zhou, Y. Zhang, W. Zhang and J. Chen, Chemosphere, 2013, 91, 717.

39 B. Karn, T. Kuiken and M. Otto, Environ. Health Perspect., 2009, 117, 1823.

40 C. C. Huang, W. T. Chia, M. F. Chung, K. J. Lin, C. W. Hsiao, C. Jin, W. H. Lim, C. C. Chen and H. W. Sung, J. Am. Chem. Soc., 2016, 138, 5222.

41 L.-H. Liu, Y.-H. Zhang, W.-X. Qiu, L. Zhang, F. Gao, B. Li, L. Xu, J.-X. Fan, Z.-H. Li and X.-Z. Zhang, Small, 2017, 13, 701621.

42 A. Turksoy, D. Yildiz and E. U. Akkaya, Coord. Chem. Rev., 2019, 379, 47.

43 H. He, S. Ji and Y. He, Adv. Mater., 2017, 29, 1606690.

44 N. Boddien, F. Gärtner, C. Federsel, P. Sponholz, D. Mellmann, R. Jackstell, H. Junge and M. Beller, Angew. Chem., Int. Ed., 2011, 50, 6411.

45 M. Zhao, Y. Xu, M. Xie, L. Zou, Z. Wang, S. Liu and Q. Zhao, Adv. Healthcare Mater., 2018, 18, 1800606. 